\title{
Periconceptional stressors and social support and risk for adverse birth outcomes
}

\author{
Kari A. Weber ${ }^{1 *}$, Suzan L. Carmichael ${ }^{1}$, Wei Yang ${ }^{1}$, Sarah C. Tinker ${ }^{2}$, Gary M. Shaw ${ }^{1}$ and National Birth Defects \\ Prevention Study
}

\begin{abstract}
Background: The prevalence of preterm birth and low birth weight has been increasing slightly in recent years. A few studies have suggested that psychosocial stress during pregnancy may increase risk for these adverse birth outcomes. To extend those observations, we analyzed various major life event stressors separately and cumulatively as potential risk factors for preterm birth and low birth weight using granular categories of each outcome in a large, population-based study. Additionally, we assessed if greater social support buffered any effects.

Methods: Data were from a nested prevalence study of 4395 women in the National Birth Defects Prevention Study who delivered live-born non-malformed infants (controls) between 2006 and 2011. Participants completed a standardized, computer-assisted interview between 6 weeks and 24 months after delivery that included questions on stress and social support from 3 months before pregnancy to the $3 \mathrm{rd}$ month of pregnancy. Cumulative stress and support indices were also calculated. Preterm birth was divided into "early preterm" (<32 weeks), "late preterm" (32-36 weeks) and "term." Low birthweight was divided into "very low birth weight" (<1500 g), "low birth weight" $(1500-2499 \mathrm{~g})$ and "normal birth weight" ( $\geq 2500 \mathrm{~g})$. Relative risks and $95 \%$ confidence intervals $(95 \% \mathrm{Cl})$ were calculated using Poisson regression.
\end{abstract}

Results: For women reporting relationship difficulties, there was a suggestive risk of early preterm birth (RR: 1.9, 95\%Cl: 0.9-3.9) and very low birthweight (RR: 2.0, 95\% Cl: 0.9-4.4). For women reporting that they or someone close to them were victims of abuse, violence, or crime, there was an increased risk of low birthweight (RR: 1.8, 95\% $\mathrm{Cl}$ : 1.1-2.7) and late preterm birth (RR: 1.5, 95\%Cl: 1.0-2.2). There were no strong associations observed between social support questions and the various outcomes.

Conclusions: Our results add some support to prior evidence that certain stressors may be associated with increase selected adverse birth outcomes risk. We did not find strong evidence that social support buffered the observed risks in our study.

Keywords: Stress, Support, Preterm, Birthweight, Maternal, Adverse pregnancy outcomes

\footnotetext{
* Correspondence: kaweber@stanford.edu

${ }^{1}$ Division of Neonatal and Developmental Medicine, Department of

Pediatrics, Stanford University School of Medicine, 1265 Welch Road x1C21,

Stanford, California 94305, USA

Full list of author information is available at the end of the article
}

C C The Author(s). 2020 Open Access This article is licensed under a Creative Commons Attribution 4.0 International License, which permits use, sharing, adaptation, distribution and reproduction in any medium or format, as long as you give appropriate credit to the original author(s) and the source, provide a link to the Creative Commons licence, and indicate if changes were made. The images or other third party material in this article are included in the article's Creative Commons licence, unless indicated otherwise in a credit line to the material. If material is not included in the article's Creative Commons licence and your intended use is not permitted by statutory regulation or exceeds the permitted use, you will need to obtain permission directly from the copyright holder. To view a copy of this licence, visit http://creativecommons.org/licenses/by/4.0/ The Creative Commons Public Domain Dedication waiver (http://creativecommons.org/publicdomain/zero/1.0/) applies to the data made available in this article, unless otherwise stated in a credit line to the data. 


\section{Background}

Roughly $10 \%$ of births in the United States are delivered preterm (before 37 weeks of gestation), and $8 \%$ of infants are born at low birthweight $(<2500 \mathrm{~g})$; the prevalence of both has been increasing slightly in recent years [1]. One potential risk factor for preterm birth and low birthweight may be maternal psychosocial stress during pregnancy. Exposure to chronic stress [2] and perceived stress [3-5] during pregnancy has been associated with preterm birth and low birthweight.

In a recent US study of 27 states, $70 \%$ of women reported experiencing at least one stressful life event in the year before giving birth [6]. Maternal stress in the form of stressful life events has been associated with preterm birth [2, 7-9] and low birthweight [5, 9, 10]. For example, a systematic literature review found women exposed to domestic violence during pregnancy to be at an increased risk for both delivering preterm and at low birthweight [11]. Further, a large Danish study found death or serious illness of close relatives early in pregnancy to be associated with an increased risk of preterm and very preterm birth [12], and pregnant women with active post-traumatic stress disorder (PTSD) were more likely to experience spontaneous preterm delivery compared to those without active PTSD [13].

The impact of individual stressors may be exacerbated in the presence of other stressors or abated by effective coping mechanisms or more social support. A prospective pregnancy cohort study in Canada observed a measure of cumulative psychosocial stress to be associated with an increased risk of late preterm birth, independent of other preterm birth risk factors [14]. When stratified by coping resources, a stronger association with higher levels of psychosocial stress was observed among women with lower perceived social support compared to those with higher levels of perceived support [14].

The current study explored stressful major life events and lack of social support (examples of data that can be efficiently collected) as potential risk factors for the outcomes of preterm birth and low birthweight employing data from controls in a large, population-based, U.S. case-control study of birth defects - The National Birth Defects Prevention Study. To explore whether different severities of preterm birth and low birthweight may have different etiologies, we used more specific sub phenotypes of these outcomes.

\section{Methods}

Data for these analyses were from the National Birth Defects Prevention Study (NBDPS). The NBDPS is a population-based, multi-center, case-control study conducted at 10 sites located in Arkansas, California, Georgia, Iowa, Massachusetts, North Carolina, New Jersey, New York, Texas, and Utah. The NBDPS methods have been described in detail elsewhere [15]. Briefly, data were collected on cases with at least one of over 30 major birth defects and about 100 live-born, non-malformed controls who were randomly selected from each center each year from vital records (AR [2000-2011], GA [2001-2011], IA, MA, NC, NJ, UT) or birth hospitals (AR [1997-2000], CA, GA [1998-2001], NY, TX). The Institutional Review Boards of each center provided approval for the NBDPS and each participant provided verbal consent prior to interview. The telephone interview process did not proceed unless the woman consented to be interviewed. Our institution's ethics board (Stanford University IRB) and the California Committee for the Protection of Human Subjects approved the use of the data analyzed in this paper.

In this analysis, we included only women delivering control infants due to the association between birth defects and preterm birth [16] and potential bias that may result from inclusion of women delivering case infants, and to be more representative of the general population of pregnant women. Participating women were administered a computer-assisted telephone interview in English or Spanish. Interviews took place between 6 weeks and 24 months after the expected date of delivery of the infant. Participation rates were 64\% among eligible controls with a mean time from delivery to interview of nine months. For this analysis, we included women with an estimated date of delivery between January 2006 and December 2011, corresponding to an update of the questionnaire to include questions on stress and social support. The questions were derived from the Kaiser Permanente/California Department of Health Study of Pregnancy and Stress and parallel existing, validated stressful life events questionnaires [17-20]. Women were eligible for inclusion in this analysis if they had a singleton pregnancy and their infants were born between 20 and 42 weeks of gestation, had a birthweight between 500 and $6000 \mathrm{~g}$, and had a birthweight within the acceptable range for the corresponding gestational week [21, 22]. There were 4678 eligible births. An additional 283 women were excluded because they were missing responses to the questions on stress, resulting in an analytic cohort of 4395 participants.

Outcomes of interest were preterm birth and low birthweight. Although preterm birth often accounts for many low birthweight infants, they were examined separately. Preterm birth was divided into "early preterm" (<32 weeks gestation), "late preterm" (32-36 weeks gestation) and "term," and low birthweight was divided into "very low birthweight" (<1500 g), "low birthweight" (1500-2499 g) and "normal birthweight" ( $\geq 2500 \mathrm{~g}$ ) [23]. Women were asked whether they experienced specific types of stress and support from three months before pregnancy through the third month of pregnancy (yes/ 
no). Stress questions related to experiencing relationship difficulties, legal/financial problems, violence/crime, illness/injury, or a relative's death. Additionally, women were asked if they had changed jobs or moved during the same time period. Support questions related to emotional support, financial help, and help with daily tasks. There was also one additional question about how often they had feelings of nervousness and stress measured on a 5-level Likert-type scale that was not included in later indices (see Appendix A for complete questions). Separate stress and support indices were created based on the cumulative number of questions for which the participant answered "yes." The stress index ranged from 0 to 7 and the support index ranged from 0 to 3 . We used the indices to create dichotomous variables for stress and social support. Participant responses skewed the stress index toward lower stress and the support index toward higher social support. Stress index values of $0-3$ were considered "low stress", while values of 4-7 were considered "high stress" after dichotomization at the median score. A support index score of 3 was considered "high support" and values of $0-2$ were considered "low support" to create a large enough group for comparison. These variables were combined to form four categories (low stress/high support, high stress/ high support, low stress/low support, and high stress/ low support). Covariates were selected a priori based on their potential relationship to the outcomes of interest and to experiences of stress: maternal race/ ethnicity, age, parity, education, pre-pregnancy body mass index $\left(\mathrm{kg} / \mathrm{m}^{2}\right)$, smoking, alcohol use, and intake of folic acid-containing vitamin/mineral supplements from the month before pregnancy through the first trimester of pregnancy.

Poisson regression with robust standard errors was used to calculate relative risks and 95\% confidence intervals. Each stress and support question was analyzed individually with "no" as the reference group. The question regarding feelings of nervousness and stress was analyzed categorically with "sometimes" as the reference group since it tended to be the most frequent response. The stress and support indices were analyzed continuously and categorically with the stress reference group being "low stress" and the support reference group being "low support." The combined index was analyzed categorically using low stress/high support as the reference group. Relative risks were calculated after adjustment for the previously selected covariates using complete case analysis.

Finally, a sensitivity analysis was performed excluding women who were taking benzodiazepines or selected antidepressants (based on those most frequently used in NBDPS $[24,25]$ to rule out potential differences in associations based on treatment.

\section{Results}

Maternal characteristics by high or low cumulative stress scores are displayed in Table 1. A greater percentage of Black, non-Hispanic women, women younger than 25 years, smokers, and women who reported binge drinking were more likely to have a high stress score. Women over the age of 30, with more than a high school diploma, and who reported no smoking or drinking alcohol were more likely to have a low stress score.

Adjusted relative risks of early and late preterm birth are presented in Table 2. For women reporting stress from relationship difficulties, there was a suggestive increased risk of early preterm birth. There was also a suggestive increased risk for women reporting feelings of nervousness or stress somewhat or very often. There were no associations observed between questions regarding social support and early or late preterm birth or any of the stress/support combinations although two of the combinations were not calculated for early preterm birth due to small sample sizes.

Adjusted relative risks of very low birthweight and low birthweight are presented in Table 3. There was a suggestive increased risk of very low birthweight for women reporting stress from relationship difficulties, feeling nervous and stressed somewhat or very often. There was an increased risk of low birthweight for women who reported they or someone close to them were victims of abuse, violence, or a crime, and a suggestive increased risk for women reporting high stress and low social support. There were no associations observed between any support questions and low birthweight.

\section{Discussion}

Overall, we did not observe individual stressful events to be moderate-to-strong risk factors for shortened gestation or having a low birthweight infant except for an increased risk of having a low birthweight infant if the woman or someone close to her was a victim of violence or crime. There were no significant associations observed between responses to social support questions and these adverse birth outcomes.

Stress could affect fetal development through a variety of mechanisms, including impacts on thrombotic and inflammatory pathways, hypoxia, oxidative stress, placental development and uterine contractility [26-28]. Stress could also affect fetal development through the neuroendocrine pathway. Measures of psychosocial stress and biological effectors of stress have been shown to predict levels of placental corticotropin-releasing-hormone and increases have been associated with spontaneous preterm labor $[28,29]$. It is possible that these mechanisms reflect chronic stress mechanisms versus more acute stress. Additionally, it is possible that unobserved fetal loss may bias our risk estimates given that psychosocial 
Table 1 Participant Characteristics (\% $\left.{ }^{\mathrm{a}}\right)$, National Birth Defects Prevention Study, 2006-2011 ( $n=4395)$

\begin{tabular}{|c|c|c|}
\hline \multirow[t]{2}{*}{ Characteristic } & \multirow{2}{*}{$\begin{array}{l}\text { Low Stress } \\
\text { Score }(0-3)^{\mathbf{b}} \\
N=4186\end{array}$} & \multirow{2}{*}{$\begin{array}{l}\text { High Stress } \\
\text { Score }(4-7)^{\mathbf{b}} \\
N=209\end{array}$} \\
\hline & & \\
\hline \multicolumn{3}{|l|}{ Race/ethnicity } \\
\hline White non-Hispanic & $2351(56.2)$ & $96(45.9)$ \\
\hline Black non-Hispanic & $404(9.7)$ & $43(20.6)$ \\
\hline Hispanic & $1131(27.0)$ & $48(23.0)$ \\
\hline Other & $299(7.1)$ & $22(10.5)$ \\
\hline Missing & $1(<0.1)$ & - \\
\hline \multicolumn{3}{|l|}{ Age (years) } \\
\hline$<20$ & $351(8.4)$ & $30(14.4)$ \\
\hline $20-24$ & $876(20.9)$ & $88(42.1)$ \\
\hline $25-29$ & $1247(29.8)$ & $45(21.5)$ \\
\hline $30-34$ & $1112(26.6)$ & $31(14.8)$ \\
\hline$>34$ & $600(14.3)$ & $15(7.2)$ \\
\hline \multicolumn{3}{|l|}{ Parity } \\
\hline Nulliparous & $1656(39.6)$ & $89(42.6)$ \\
\hline Parous & $2529(60.4)$ & $120(57.4)$ \\
\hline Missing & $1(<0.1)$ & - \\
\hline \multicolumn{3}{|l|}{ Education } \\
\hline$<$ High school & $658(15.7)$ & $32(15.3)$ \\
\hline High school graduate & $917(21.9)$ & $81(38.8)$ \\
\hline$>$ High school & $2602(62.2)$ & $96(45.9)$ \\
\hline Missing & $9(0.2)$ & - \\
\hline \multicolumn{3}{|l|}{ Smoking ${ }^{c}$} \\
\hline No & $3559(85.0)$ & $108(51.7)$ \\
\hline Yes & $625(14.9)$ & $101(48.3)$ \\
\hline Missing & $2(<0.1)$ & - \\
\hline \multicolumn{3}{|c|}{ Use of folic acid-containing vitamin/mineral supplement } \\
\hline Began month before or 1st month & $2423(57.9)$ & $86(41.2)$ \\
\hline Began 2nd - 3rd month & $1277(30.5)$ & 79 (37.8) \\
\hline Began later or none & $447(10.7)$ & $41(19.6)$ \\
\hline Missing & $39(0.9)$ & $3(1.4)$ \\
\hline \multicolumn{3}{|l|}{ Alcohol use ${ }^{c}$} \\
\hline None & $2611(62.4)$ & $103(49.3)$ \\
\hline Some & $1029(24.6)$ & $48(23.0)$ \\
\hline Binge drinking ${ }^{d}$ & $511(12.2)$ & $57(27.3)$ \\
\hline Missing & $35(0.8)$ & $1(0.5)$ \\
\hline \multicolumn{3}{|c|}{ Pre-pregnancy body mass index $\left(\mathrm{kg} / \mathrm{m}^{2}\right)$} \\
\hline Underweight $(<18.5)$ & $200(4.8)$ & $10(4.8)$ \\
\hline Normal weight (18.5-24.9) & $2041(48.8)$ & $91(43.5)$ \\
\hline Overweight (25.0-29.9) & $925(22.1)$ & $48(23.0)$ \\
\hline Obese $(>=30.0)$ & $849(20.3)$ & $55(26.3)$ \\
\hline Missing & $171(4.1)$ & $5(2.4)$ \\
\hline
\end{tabular}

a Numbers may not add to $100 \%$ due to rounding

b Indices reflect the number of questions that had a "yes" response

' From one month before through three months after conception

${ }^{d}$ Having four or more drinks on at least one occasion stress has been associated with miscarriage in some studies [30]. To attempt to assess this hypothesis, we performed an ad hoc effect modification analysis to estimate if risk of preterm birth is modified by infant sex. It has been posited that male fetuses may be more likely to be "culled," i.e. before they can be observed to occur as a fetal death or live birth, in response to stressors [31, 32]. We observed higher risks of preterm birth for female infants among women experiencing relationship difficulties, job changes, and measuring high $(\geq 4$ "yes" responses) on the stress index (results not shown). We also observed higher risks for female infants born to women experiencing high stress/low support (ARR 3.0 vs. 0.67 ; $\mathrm{p}$-heterogeneity $=0.05$ ). These results support this hypothesis, which could explain some of the null findings if the pregnancies with male fetuses were more likely to result in fetal loss in response to psychosocial stress. However, infant sex differences may also be due to differences in reactions to stressors, inflammation, or other factors.

The associations observed between women who reported they or someone close to them were victims of abuse, violence, or a crime and low birthweight and the suggestive associations between relationship difficulties and very low birthweight and preterm birth support results from the literature. Previous studies have reported associations between abuse and adverse pregnancy outcomes, with both physical and psychological mechanisms proposed [11,33]. Exposure to violence or crime and relationship issues may both encompass a level of domestic or other abuse although our questionnaire did not elicit this level of specificity. A previous study of more specific major life events also observed both negative and positive associations with birthweight, depending on the stressful event [5]. While our results were not as heterogeneous, it is possible that different events lend themselves to different levels or chronicity of stress.

Previous studies of maternal social support and low birthweight have had conflicting results [34, 35]. We observed a suggestive association between high stress/low support and having a low birthweight infant but not preterm birth as seen in a previous study [14]. However, we were unable to calculate ARR estimates for a few of the combinations of stress and social support for the more severe adverse outcomes due to sample size. Additionally, we were also unable to calculate specific combinations of stress and social support (i.e., specific life events and types of support) due to sample size and cannot rule out social support being a buffer of certain stressful life events and not others. McDonald et al. utilized data from more detailed questionnaires to measure stress and social support and thus may have been better able to discriminate between those with high and low levels of social support [14]. Many of our participants also 
Table 2 Association of Stressful Life Events and Social Support with Preterm Birth, NBDPS, 2006-2011

\begin{tabular}{|c|c|c|c|c|c|}
\hline \multirow[t]{2}{*}{ Exposures } & $\begin{array}{l}\text { Total } \\
(\boldsymbol{N}=4134)\end{array}$ & $\begin{array}{l}\text { Early Preterm } \\
(\boldsymbol{N}=38)\end{array}$ & \multirow[t]{2}{*}{$\begin{array}{l}\mathrm{ARR}^{\mathbf{a}} \\
(95 \% \mathrm{Cl})\end{array}$} & $\begin{array}{l}\text { Late Preterm } \\
(\boldsymbol{N}=266)\end{array}$ & \multirow[t]{2}{*}{$\begin{array}{l}\mathrm{ARR}^{\mathbf{a}} \\
(95 \% \mathrm{Cl})\end{array}$} \\
\hline & No. & No. (row \%) & & No. (row \%) & \\
\hline \multicolumn{6}{|l|}{ Stressful life events ${ }^{b}$} \\
\hline \multicolumn{6}{|l|}{ Relationship difficulties } \\
\hline No & 3432 & $27(0.8)$ & Referent & $211(6.1)$ & Referent \\
\hline Yes & 702 & $11(1.6)$ & $1.9(0.9,3.9)$ & $55(7.8)$ & $1.2(0.8,1.6)$ \\
\hline \multicolumn{6}{|l|}{ Legal/financial problems } \\
\hline No & 3577 & $31(0.9)$ & Referent & $220(6.2)$ & Referent \\
\hline Yes & 557 & $7(1.3)$ & $1.5(0.6,3.4)$ & $46(8.3)$ & $1.2(0.9,1.7)$ \\
\hline \multicolumn{6}{|l|}{ Violence/crime } \\
\hline No & 3843 & $36(0.9)$ & Referent & $237(6.2)$ & Referent \\
\hline Yes & 291 & $2(0.7)$ & NC & $29(10.0)$ & $1.5(1.0,2.2)$ \\
\hline \multicolumn{6}{|l|}{ Illness/injury } \\
\hline No & 3550 & $32(0.9)$ & Referent & $224(6.3)$ & Referent \\
\hline Yes & 584 & $6(1.0)$ & $1.1(0.4,2.6)$ & $42(7.2)$ & $1.2(0.8,1.6)$ \\
\hline \multicolumn{6}{|l|}{ Death of someone close } \\
\hline No & 3509 & $34(1.0)$ & Referent & $221(6.3)$ & Referent \\
\hline Yes & 625 & $4(0.6)$ & $0.6(0.2,1.6)$ & $45(7.2)$ & $1.1(0.8,1.5)$ \\
\hline \multicolumn{6}{|l|}{ Changed jobs } \\
\hline No & 3111 & $29(0.9)$ & Referent & $199(6.4)$ & Referent \\
\hline Yes & 1023 & $9(0.9)$ & $0.9(0.4,1.9)$ & $67(6.5)$ & $1.0(0.7,1.3)$ \\
\hline \multicolumn{6}{|l|}{ Moved } \\
\hline No & 3429 & $30(0.9)$ & Referent & $210(6.1)$ & Referent \\
\hline Yes & 705 & $8(1.1)$ & $1.1(0.5,2.5)$ & $56(7.9)$ & $1.2(0.9,1.7)$ \\
\hline \multicolumn{6}{|c|}{ Feelings of nervousness and stress } \\
\hline Never or almost never & 1181 & $8(0.7)$ & $0.9(0.4,2.3)$ & $65(5.5)$ & $0.9(0.6,1.2)$ \\
\hline Sometimes & 1728 & $13(0.8)$ & Referent & $108(6.3)$ & Referent \\
\hline Somewhat or very often & 1225 & $17(1.4)$ & $2.0(1.0,4.1)$ & $93(7.6)$ & $1.2(0.9,1.6)$ \\
\hline \multicolumn{6}{|l|}{ Stress index ${ }^{c}$} \\
\hline Low stress $(0-3)$ & 3934 & $36(0.9)$ & Referent & $246(6.3)$ & Referent \\
\hline High stress (4-7) & 200 & $2(1.0)$ & NC & $20(10.0)$ & $1.4(0.9,2.3)$ \\
\hline \multicolumn{6}{|l|}{ Social support ${ }^{b}$} \\
\hline \multicolumn{6}{|l|}{ Emotional support } \\
\hline No & 505 & $7(1.4)$ & Referent & $38(7.5)$ & Referent \\
\hline Yes & 3629 & $31(0.9)$ & $0.7(0.3,1.7)$ & $228(6.3)$ & $1.0(0.7,1.4)$ \\
\hline \multicolumn{6}{|l|}{ Financial support } \\
\hline No & 601 & $7(1.2)$ & Referent & $42(7.0)$ & Referent \\
\hline Yes & 3533 & $31(0.9)$ & $0.8(0.3,2.0)$ & $224(6.3)$ & $1.1(0.8,1.5)$ \\
\hline \multicolumn{6}{|l|}{ Help with daily tasks } \\
\hline No & 573 & $5(0.9)$ & Referent & $40(7.0)$ & Referent \\
\hline Yes & 3561 & $33(0.9)$ & $1.2(0.4,3.1)$ & $226(6.3)$ & $1.0(0.7,1.5)$ \\
\hline \multicolumn{6}{|l|}{ Social support index ${ }^{c}$} \\
\hline Low support (0-2) & 984 & $13(1.3)$ & Referent & $71(7.2)$ & Referent \\
\hline High support (3) & 3150 & $25(0.8)$ & $0.7(0.3,1.4)$ & $195(6.2)$ & $1.0(0.7,1.3)$ \\
\hline
\end{tabular}


Table 2 Association of Stressful Life Events and Social Support with Preterm Birth, NBDPS, 2006-2011 (Continued)

\begin{tabular}{|c|c|c|c|c|c|}
\hline \multirow[t]{2}{*}{ Exposures } & $\begin{array}{l}\text { Total } \\
(\boldsymbol{N}=4134)\end{array}$ & $\begin{array}{l}\text { Early Preterm } \\
(\boldsymbol{N}=38)\end{array}$ & \multirow[t]{2}{*}{$\begin{array}{l}\mathrm{ARR}^{\mathbf{a}} \\
(95 \% \mathrm{Cl})\end{array}$} & $\begin{array}{l}\text { Late Preterm } \\
(\boldsymbol{N}=266)\end{array}$ & \multirow[t]{2}{*}{$\begin{array}{l}\mathrm{ARR}^{\mathbf{a}} \\
(95 \% \mathrm{Cl})\end{array}$} \\
\hline & No. & No. (row \%) & & No. (row \%) & \\
\hline \multicolumn{6}{|c|}{ Stress and social support combined ${ }^{d}$} \\
\hline Low stress, high support & 3039 & $24(0.8)$ & Referent & $185(6.1)$ & Referent \\
\hline High stress, high support & 111 & $1(0.9)$ & NC & $10(9.0)$ & $1.3(0.7,2.5)$ \\
\hline Low stress, low support & 895 & $12(1.3)$ & $1.5(0.7,3.2)$ & $61(6.8)$ & $1.0(0.7,1.3)$ \\
\hline High stress, low support & 89 & $1(1.1)$ & NC & $10(11.2)$ & $1.5(0.8,3.0)$ \\
\hline
\end{tabular}

Abbreviations: $A R R$ adjusted relative risk, $\mathrm{Cl}$ confidence interval, NC not calculated

${ }^{\text {a }}$ Relative risks were adjusted for maternal race/ethnicity, age, parity, education, prepregnancy body mass index $\left(\mathrm{kg} / \mathrm{m}^{2}\right)$, smoking, alcohol use, and intake of folic acid-containing supplements from the month before pregnancy through the first trimester of pregnancy

${ }^{b}$ Complete questions can be found in Appendix A

"Indices reflect the number of questions that had a "yes" response

d Women were designated as having low stress if the stressful life events index score was 0-3 and as having high stress if it was 4-7. Women were designated as having low social support if the social support index score was $0-2$ and as having high support if it was 3

responded yes to all of the social support questions, limiting comparisons between low and high social support.

Medication for stress-related disorders such as anxiety and depression have been associated with preterm birth and low birthweight in some studies. In one review, antidepressant use later in gestation was associated with preterm birth, independent of depression [36]. In another study, benzodiazepine use was associated with low birthweight and both benzodiazepine use, and serotonin reuptake inhibitor use appeared to be associated with shortened gestation [37]. To assess potential effects of medication use on any observed associations, we performed a sensitivity analysis excluding 266 women who were taking any of the commonly used benzodiazepines (alprazolam, clonazepam, diazepam, and lorazepam) or selective-serotonin reuptake inhibitors (sertraline, paroxetine, fluoxetine, escitalopram, or citalopram), or bupropion. However, we did not observe a substantial change in risk after excluding women reporting use of these medications (data not shown).

One limitation of this study is that the interview asks about the presence or absence of selected stressors without taking into account duration or chronic nature of the stressor and thus may be a better measure of acute versus chronic stress. It is possible that some of the women responding yes to certain questions did not experience a level of stress of sufficient intensity to impact pregnancy outcomes. The questions also ask if the woman or someone close to her experienced some of the stressful situations. It is possible that stress in response to the situation of another person may impact a pregnancy in different ways than direct stress to oneself. The questions also asked for a participant's experience during a specific point in gestation from pre to early pregnancy. One study observed that only perceived stress during the second trimester was associated with preterm birth [38], which we would not be able to estimate in this study. Based on the nature of the retrospective data collection, recall is also a potential issue as well as social desirability bias, or an unwillingness to report certain negative experiences. However, this study focused on major life events which helped to limit potential biases. Additionally, small sample size for some outcome groups and low prevalence of stressful life events hindered calculation of certain risks.

Strengths of this study include the population-based sample and standardized interview examining multiple possible situations of stress and social support. The questionnaire examined these situations utilizing major life events that are relatively common and easy to recall among women who are representative of the general population. While we did not observe specific associations for many of the separate stress or support questions, we gained some insight regarding the potential association with cumulative stressors. The indices were created based on the assumption that effects of stressful and supportive life events are additive [39], and we did observe some positive associations with a greater number of stressful events. It is possible that our results point to a greater stress load rather than specific stressful events as related to adverse birth outcomes. We also examined adverse birth outcomes more granularly than simply low birthweight or preterm birth. Although sample size was limited for early preterm birth and very low birthweight, the differences in results between the different subgroups of low birthweight and preterm birth add support to the hypothesis that differences by severity are due to different etiologies. Preterm births were likely the cause of some of the low birth weights in this population. We considered low birthweight instead of small for gestational age in order to better match outcomes used in other studies, allowing our data to better contribute to the synthesis of data across studies. Our sample was also randomly sampled from each study centers' 
Table 3 Association of Stressful Life Events and Social Support with Low Birthweight, NBDPS, 2006-2011

\begin{tabular}{|c|c|c|c|c|c|}
\hline \multirow[t]{2}{*}{ Exposures } & \multirow{2}{*}{$\begin{array}{l}\text { Total } \\
(\boldsymbol{N}=4134) \\
\text { No. }\end{array}$} & \multirow{2}{*}{$\begin{array}{l}\text { Very Low } \\
\text { Birthweight } \\
(\boldsymbol{N}=31) \\
\text { No. (row \%) }\end{array}$} & \multirow[t]{2}{*}{$\begin{array}{l}\mathrm{ARR}^{\mathbf{a}} \\
(95 \% \mathrm{CI})\end{array}$} & $\begin{array}{l}\text { Low Birthweight } \\
(\boldsymbol{N}=182)\end{array}$ & \multirow[t]{2}{*}{$\begin{array}{l}\mathrm{ARR}^{\mathbf{a}} \\
(95 \% \mathrm{Cl})\end{array}$} \\
\hline & & & & \multirow{2}{*}{\multicolumn{2}{|c|}{ No. (row \%) }} \\
\hline \multicolumn{4}{|l|}{ Stressful life events ${ }^{\mathbf{b}}$} & & \\
\hline \multicolumn{6}{|l|}{ Relationship difficulties } \\
\hline No & 3432 & $21(0.6)$ & Referent & $144(4.2)$ & Referent \\
\hline Yes & 702 & $10(1.4)$ & $2.0(0.9,4.4)$ & $38(5.4)$ & $1.0(0.7,1.5)$ \\
\hline \multicolumn{6}{|l|}{ Legal/financial problems } \\
\hline No & 3577 & $25(0.7)$ & Referent & $152(4.2)$ & Referent \\
\hline Yes & 557 & $6(1.1)$ & $1.6(0.6,3.9)$ & $30(5.4)$ & $1.2(0.8,1.8)$ \\
\hline \multicolumn{6}{|l|}{ Violence/crime } \\
\hline No & 3843 & $29(0.8)$ & Referent & $157(4.1)$ & Referent \\
\hline Yes & 291 & $2(0.7)$ & NC & $25(8.6)$ & $1.8(1.1,2.7)$ \\
\hline \multicolumn{6}{|l|}{ Illness/injury } \\
\hline No & 3550 & $25(0.7)$ & Referent & $162(4.6)$ & Referent \\
\hline Yes & 584 & $6(1.0)$ & $1.3(0.5,3.3)$ & $20(3.4)$ & $0.7(0.5,1.2)$ \\
\hline \multicolumn{6}{|l|}{ Death of someone close } \\
\hline No & 3509 & $29(0.8)$ & Referent & $153(4.4)$ & Referent \\
\hline Yes & 625 & $2(0.3)$ & NC & $29(4.6)$ & $1.0(0.7,1.5)$ \\
\hline \multicolumn{6}{|l|}{ Changed jobs } \\
\hline No & 3111 & $24(0.8)$ & Referent & $136(4.4)$ & Referent \\
\hline Yes & 1023 & $7(0.7)$ & $0.7(0.3,1.7)$ & $46(4.5)$ & $0.9(0.6,1.3)$ \\
\hline \multicolumn{6}{|l|}{ Moved } \\
\hline No & 3429 & $24(0.7)$ & Referent & $153(4.5)$ & Referent \\
\hline Yes & 705 & $7(1.0)$ & $1.1(0.5,2.7)$ & $29(4.1)$ & $0.8(0.5,1.2)$ \\
\hline \multicolumn{6}{|c|}{ Feelings of nervousness and stress } \\
\hline Never or almost never & 1181 & $6(0.5)$ & $0.9(0.3,2.5)$ & $40(3.4)$ & $0.8(0.5,1.2)$ \\
\hline Sometimes & 1728 & $10(0.6)$ & Referent & $74(4.3)$ & Referent \\
\hline Somewhat or very often & 1225 & $15(1.2)$ & $2.2(1.0,5.0)$ & $68(5.6)$ & $1.3(0.9,1.8)$ \\
\hline \multicolumn{6}{|l|}{ Stress index ${ }^{c}$} \\
\hline Low stress $(0-3)$ & 3934 & $29(0.7)$ & Referent & $168(4.3)$ & Referent \\
\hline High stress (4-7) & 200 & $2(1.0)$ & NC & $14(7.0)$ & $1.3(0.7,2.3)$ \\
\hline \multicolumn{6}{|l|}{ Social support ${ }^{b}$} \\
\hline \multicolumn{6}{|l|}{ Emotional support } \\
\hline No & 505 & $5(1.0)$ & Referent & $31(6.1)$ & Referent \\
\hline Yes & 3629 & $26(0.7)$ & $0.8(0.3,2.3)$ & $151(4.2)$ & $0.8(0.5,1.1)$ \\
\hline \multicolumn{6}{|l|}{ Financial support } \\
\hline No & 601 & $3(0.5)$ & Referent & $29(4.8)$ & Referent \\
\hline Yes & 3533 & $28(0.8)$ & $1.8(0.5,6.1)$ & $153(4.3)$ & $0.9(0.6,1.4)$ \\
\hline \multicolumn{6}{|l|}{ Help with daily tasks } \\
\hline No & 573 & $5(0.9)$ & Referent & $28(4.9)$ & Referent \\
\hline Yes & 3561 & $26(0.7)$ & $0.9(0.3,2.5)$ & $154(4.3)$ & $1.0(0.6,1.4)$ \\
\hline \multicolumn{6}{|l|}{ Social support index ${ }^{c}$} \\
\hline Low support (0-2) & 984 & $8(0.8)$ & Referent & $53(5.4)$ & Referent \\
\hline High support (3) & 3150 & $23(0.7)$ & $1.0(0.4,2.4)$ & $129(4.1)$ & $0.8(0.6,1.1)$ \\
\hline
\end{tabular}


Table 3 Association of Stressful Life Events and Social Support with Low Birthweight, NBDPS, 2006-2011 (Continued)

\begin{tabular}{|c|c|c|c|c|c|}
\hline \multirow[t]{2}{*}{ Exposures } & $\begin{array}{l}\text { Total } \\
(\boldsymbol{N}=4134)\end{array}$ & $\begin{array}{l}\text { Very Low } \\
\text { Birthweight } \\
(\boldsymbol{N}=31)\end{array}$ & $\begin{array}{l}\operatorname{ARR}^{\mathbf{a}} \\
(95 \% \mathrm{Cl})\end{array}$ & $\begin{array}{l}\text { Low Birthweight } \\
(\boldsymbol{N}=182)\end{array}$ & \multirow[t]{2}{*}{$\begin{array}{l}\mathrm{ARR}^{\mathbf{a}} \\
(95 \% \mathrm{Cl})\end{array}$} \\
\hline & No. & \multicolumn{2}{|l|}{ No. (row \%) } & No. (row \%) & \\
\hline \multicolumn{6}{|c|}{ Stress and social support combined $^{d}$} \\
\hline Low stress, high support & 3039 & $22(0.7)$ & Referent & $124(4.1)$ & Referent \\
\hline High stress, high support & 111 & $1(0.9)$ & NC & $5(4.5)$ & $0.9(0.4,2.2)$ \\
\hline Low stress, low support & 895 & $7(0.8)$ & $0.9(0.4,2.4)$ & $44(4.9)$ & $1.2(0.8,1.7)$ \\
\hline High stress, low support & 89 & $1(1.1)$ & NC & $9(10.1)$ & $1.9(1.0,3.9)$ \\
\hline
\end{tabular}

Abbreviations: $A R R$ adjusted relative risk, $\mathrm{Cl}$ confidence interval, NC not calculated

${ }^{a}$ Relative risks were adjusted for maternal race/ethnicity, age, parity, education, prepregnancy body mass index $\left(\mathrm{kg} / \mathrm{m}^{2}\right)$, smoking, alcohol use, and intake of folic acid-containing supplements from the month before pregnancy through the first trimester of pregnancy

${ }^{b}$ Complete questions can be found in Appendix A

"Indices reflect the number of questions that had a "yes" response

${ }^{d}$ Women were designated as having low stress if the stressful life events index score was 0-3 and as having high stress if it was 4-7. Women were designated as having low social support if the social support index score was 0-2 and as having high support if it was 3

catchment area and thus should be generalizable to these 10 areas throughout the US, though not the entire US.

Given that exposure to stress is relatively common, and that social support may not be adequate to attenuate potential harm due to stress, it is important to continue to understand the effects of various types of stress, both acute and chronic, in different populations and what methods of support or treatment may buffer its negative effects. It is important to keep developing ways to improve mental wellbeing, particularly during pregnancy.

\section{Conclusions}

Our results add some support to prior evidence that certain stressors, like being or knowing a victim of violence or a crime, may be associated with an increased risk of selected adverse birth outcomes. We did not find strong evidence that social support buffered the observed risks in our study but given the high levels of perceived social support in our population, we may not have had an adequate distribution to fully investigate its potential effects.

\section{Supplementary information}

Supplementary information accompanies this paper at https://doi.org/10. 1186/s12884-020-03182-6.

Additional file 1. Questions Related to Stressful Life Events and Social Support in the National Birth Defects Prevention Study from 3 months before pregnancy through the $3 r d$ month of pregnancy.

\section{Abbreviations}

PTSD: Post-traumatic stress disorder; NBDPS: National Birth Defects Prevention Study; RR: Relative risk; Cl: Confidence interval

\section{Acknowledgements}

We thank the California Department of Public Health, Maternal Child and Adolescent Health Division for providing surveillance data from California for this study.

\section{Authors' contributions}

All authors have read the manuscript, agree the work is ready for submission, and accept responsibility for the manuscript's contents. KW designed the analysis, interpreted the data and drafted the manuscript. SC substantially contributed to the conception and design of this work and substantially revised the manuscript. WY analyzed and interpreted the data. ST substantially contributed to the conception and design of this work and substantially revised the manuscript. GS substantially contributed to the conception and design of this work and substantially revised the manuscript.

\section{Funding}

This work was supported by the Centers for Disease Control and Prevention Centers of Excellence No. U01DD001033. This project was supported through Centers for Disease Control and Prevention (CDC) cooperative agreements under PA \#96043, PA \#02081, FOA \#DD09-001, FOA \#DD13-003, and NOFO \#DD18-001 to the Centers for Birth Defects Research and Prevention participating in the National Birth Defects Prevention Study (NBDPS) and/or the Birth Defects Study To Evaluate Pregnancy exposureS (BD-STEPS). The findings and conclusions in this report are those of the authors and do not necessarily represent the official position of the Centers for Disease Control and Prevention or the California Department of Public Health.

\section{Availability of data and materials}

The datasets generated and/or analysed during the current study are not publicly available to guarantee the confidentiality of participants and to ensure that data are used in accordance with their consented purposes but are available from the corresponding author on reasonable request. https:// www.cdc.gov/ncbddd/birthdefects/nbdps-public-access-procedures.html

\section{Ethics approval and consent to participate}

We have adhered to ethical standards in this work and obtained Institutional Review Board approval for use of human subjects' data. The Institutional Review Boards of each center provided approval for the NBDPS (Arkansas, California, Georgia, lowa, Massachusetts, North Carolina, New Jersey, New York, Texas, and Utah). Our institution's ethics boards (California Committee for the Protection of Human Subjects (Protocol 13-04-1172) and Stanford University IRB (protocol 17085) approved the use of the data analyzed in this paper. Verbal informed consent was obtained at the initiation of the telephone interview for each woman. Verbal consent to participate in this multicentered study (in lieu of written consent) was approved by each institution's Institutional Review Board based on the rationale that: 1) the study involved a telephone interview only; 2 ) given the study's large size ( 50,000 women) the costs to obtain written consent were prohibitive; and 3 ) request for written consent would be an additional burden to study subjects. The computer-assisted interview process did not proceed unless the woman consented to be interviewed.

\section{Consent for publication} NA 


\section{Competing interests}

All authors have no conflict of interest to declare.

\section{Author details}

'Division of Neonatal and Developmental Medicine, Department of Pediatrics, Stanford University School of Medicine, 1265 Welch Road x1C21, Stanford, California 94305, USA. ${ }^{2}$ National Center on Birth Defects and Developmental Disabilities, Centers for Disease Control and Prevention, Atlanta, GA, USA.

Received: 7 January 2020 Accepted: 16 August 2020

Published online: 24 August 2020

\section{References}

1. Hamilton BE, Martin JA, Osterman MJK. Births: Preliminary data for 2015 National vital statistics reports; vol 65 no 3,. National Center for Health Statistics; 2016.

2. Dunkel SC. Psychological science on pregnancy: stress processes, biopsychosocial models, and emerging research issues. Annu Rev Psychol. 2011:62:531-58

3. Staneva A, Bogossian F, Pritchard M, Wittkowski A. The effects of maternal depression, anxiety, and perceived stress during pregnancy on preterm birth: a systematic review. Women and birth : journal of the Australian College of Midwives. 2015;28(3):179-93.

4. Rondo PH, Ferreira RF, Nogueira F, Ribeiro MC, Lobert H, Artes R. Maternal psychological stress and distress as predictors of low birth weight, prematurity and intrauterine growth retardation. Eur J Clin Nutr. 2003;57(2):266-72

5. Sable MR, Wilkinson DS. Impact of perceived stress, major life events and pregnancy attitudes on low birth weight. Fam Plan Perspect. 2000; 32(6):288-94.

6. Burns ER, Farr SL, Howards PP. Stressful life events experienced by women in the year before their infants' births--United States, 2000-2010. MMWR Morb Mortal Wkly Rep. 2015;64(9):247-51.

7. Witt WP, Cheng ER, Wisk LE, Litzelman K, Chatterjee D, Mandell K, et al. Preterm birth in the United States: the impact of stressful life events prior to conception and maternal age. Am J Public Health. 2014; 104(Suppl 1):S73-80

8. Dole N, Savitz DA, Hertz-Picciotto I, Siega-Riz AM, McMahon MJ, Buekens P. Maternal stress and preterm birth. Am J Epidemiol. 2003;157(1):14-24.

9. Zhu P, Tao F, Hao J, Sun Y, Jiang X. Prenatal life events stress: implications for preterm birth and infant birthweight. Am J Obstet Gynecol. 2010;203(1): 34 e1-8.

10. Witt WP, Cheng ER, Wisk LE, Litzelman K, Chatterjee D, Mandell K, et al. Maternal stressful life events prior to conception and the impact on infant birth weight in the United States. Am J Public Health. 2014;104(Suppl 1): S81-9.

11. Shah PS, Shah J. Maternal exposure to domestic violence and pregnancy and birth outcomes: a systematic review and meta-analyses. J Women's Health (2002). 2010;19(11):2017-31.

12. Khashan AS, McNamee R, Abel KM, Mortensen PB, Kenny LC, Pedersen MG, et al. Rates of preterm birth following antenatal maternal exposure to severe life events: a population-based cohort study. Human Reprod (Oxford, England). 2009:24(2):429-37.

13. Shaw JG, Asch SM, Kimerling R, Frayne SM, Shaw KA, Phibbs CS. Posttraumatic stress disorder and risk of spontaneous preterm birth. Obstet Gynecol. 2014;124(6):1111-9.

14. McDonald SW, Kingston D, Bayrampour H, Dolan SM, Tough SC. Cumulative psychosocial stress, coping resources, and preterm birth. Arch Women's Mental HSealth. 2014;17(6):559-68.

15. Reefhuis J, Gilboa SM, Anderka M, Browne ML, Feldkamp ML, Hobbs CA, et al. The National Birth Defects Prevention Study: a review of the methods. Birth Defects Res Part A, Clin Mol Teratol. 2015;103(8):656-69.

16. Honein MA, Kirby RS, Meyer RE, Xing J, Skerrette NI, Yuskiv N, et al. The association between major birth defects and preterm birth. Matern Child Health J. 2009;13(2):164-75.

17. Carmichael SL, Shaw GM, Yang W, Abrams B, Lammer EJ, et al. Epidemiology (Cambridge, Mass). 2007;18(3):356-61.

18. Holmes $\mathrm{TH}$, Rahe $\mathrm{RH}$. The social readjustment rating scale. J Psychosom Res. $1967 ; 11(2): 213-8$
19. Sarason IG, Johnson JH, Siegel JM. Assessing the impact of life changes: development of the life experiences survey. J Consult Clin Psychol. 1978; 46(5):932-46.

20. Newton RW, Hunt LP. Psychosocial stress in pregnancy and its relation to low birth weight. Br Med J (Clin Res Ed). 1984;288(6425):1191-4.

21. Alexander GR, Himes JH, Kaufman RB, Mor J, Kogan M. A United States national reference for fetal growth. Obstet Gynecol. 1996;87(2):163-8.

22. Oken E, Kleinman KP, Rich-Edwards J, Gillman MW. A nearly continuous measure of birth weight for gestational age using a United States national reference. BMC Pediatr. 2003;3:6.

23. Cogswell ME, Bitsko RH, Anderka M, Caton AR, Feldkamp ML, Hockett Sherlock SM, et al. Control selection and participation in an ongoing, population-based, case-control study of birth defects: the National Birth Defects Prevention Study. Am J Epidemiol. 2009;170(8):975-85.

24. Alwan S, Reefhuis J, Rasmussen SA, Friedman JM. Patterns of antidepressant medication use among pregnant women in a United States population. J Clin Pharmacol. 2011:51(2):264-70.

25. Reefhuis et al. Specific SSRIs and birth defects: Bayesian analysis to interpret new data in the context of previous reports. BMJ. 2015;350:h3190:1-8.

26. Brunton PJ. Effects of maternal exposure to social stress during pregnancy: consequences for mother and offspring. Reproduction (Cambridge, England). 2013;146(5):R175-89.

27. Olson DM, Severson EM, Verstraeten BS, Ng JW, McCreary JK, Metz GA Allostatic load and preterm birth. Int J Mol Sci. 2015;16(12):29856-74.

28. Shapiro GD, Fraser WD, Frasch MG, Seguin JR. Psychosocial stress in pregnancy and preterm birth: associations and mechanisms. J Perinat Med. 2013;41(6):631-45

29. Wadhwa PD, Entringer S, Buss C, Lu MC. The contribution of maternal stress to preterm birth: issues and considerations. Clin Perinatol. 2011;38(3):351-84

30. Qu F, Wu Y, Zhu YH, Barry J, Ding T, Baio G, et al. The association between psychological stress and miscarriage: a systematic review and meta-analysis. Sci Rep. 2017;7(1):1731

31. Bruckner T, Catalano R. The sex ratio and age-specific male mortality: evidence for culling in utero. Am J Human Biol. 2007;19(6):763-73.

32. Bruckner TA, Catalano R. Selection in utero and population health: theory and typology of research. SSM - Population hHalth. 2018;5:101-13.

33. Newberger EH, Barkan SE, Lieberman ES, McCormick MC, Yllo K, Gary LT, et al. Abuse of pregnant women and adverse birth outcome. Current knowledge and implications for practice. Jama. 1992;267(17):2370-2.

34. Nylen KJ, O'Hara MW, Engeldinger J. Perceived social support interacts with prenatal depression to predict birth outcomes. J Behav Med. 2013;36(4): 427-40.

35. Feldman PJ, Dunkel-Schetter C, Sandman CA, Wadhwa PD. Maternal social support predicts birth weight and fetal growth in human pregnancy. Psychosom Med. 2000;62(5):715-25.

36. Huybrechts KF, Sanghani RS, Avorn J, Urato AC. Preterm birth and antidepressant medication use during pregnancy: a systematic review and meta-analysis. PLoS One. 2014;9(3):e92778.

37. Yonkers KA, Gilstad-Hayden K, Forray A, Lipkind HS. Association of Panic Disorder, Generalized Anxiety Disorder, and Benzodiazepine Treatment During Pregnancy With Risk of Adverse Birth Outcomes. JAMA psychiatry. 2017.

38. Hoffman MC, Mazzoni SE, Wagner BD, Laudenslager ML, Ross RG. Measures of maternal stress and mood in relation to preterm birth. Obstet Gynecol. 2016:127(3):545-52.

39. McLean DE, Hatfield-Timajchy K, Wingo PA, Floyd RL. Psychosocial measurement: implications for the study of preterm delivery in black women. Am J Prev Med. 1993;9(6 Suppl):39-81.

\section{Publisher's Note}

Springer Nature remains neutral with regard to jurisdictional claims in published maps and institutional affiliations. 